\title{
NIH may open access to clinical facility
}

\section{Outside investigators could pay to use the Clinical Center's state-of-the-art resources.}

During 14 years at the US National Institutes of Health (NIH), surgical oncologist Steven Libutti took full advantage of the imposing research hospital that dominates the skyline on the agency's campus in Bethesda, Maryland. When running human trials at the Clinical Center, Libutti had at his disposal an on-site cyclotron for making medical isotopes, nurses available to take blood and urine samples every $15 \mathrm{~min}$ utes to measure the processing of experimental drugs, and state-of-the-art imaging equipment free from the competing demands of physicians wanting to use it for clinical care.

Things changed dramatically for Libutti when he left the NIH. As director of the MontefioreEinstein Center for Cancer Care in New York, he recently spent eight months just trying to get a clinical trial off the ground, looking after details as small as finding a way for subjects to come and have their blood drawn at the hospital at a weekend. Now the NIH is considering a proposal that would give outside investigators such as Libutti the same access as its own researchers to the research hospital, with its annual budget of US\$386 million. “The Clinical Center is an incredibly valuable resource; there are things you can do there that would be difficult or impossible to do on the outside," says Libutti.

The proposal is part of a sweeping examination of the fiscal sustainability and utilization of the Clinical Center being conducted by the NIH's Scientific Management Review Board (SMRB), a panel of advisers to NIH director Francis Collins.

The board is confronting a seemingly intractable trend: the costs of care at the Clinical Center have been climbing far faster than the budgets of the 17 institutes on the Bethesda campus that use it (see 'Soaring costs'). Each institute pays an annual fee called a 'school tax', pegged to the size of its intramural research budget, for running as many trials as it chooses in the centre. But the institutes are increasingly being asked to pay surcharges for items ranging from scans to drugs to genetic tests. (Unlike the hospitals at academic medical centres, the Clinical Center has no paying patients, only non-paying research subjects.)

The shift in costs has caused institutes to avoid running some trials; weekday occupancy rates in the past five years have dipped as low as $64 \%$ despite the attractions of the new state-of-the-art building that opened in 2004. "The reason there aren't more patients," says John Gallin, the director of the Clinical Center,

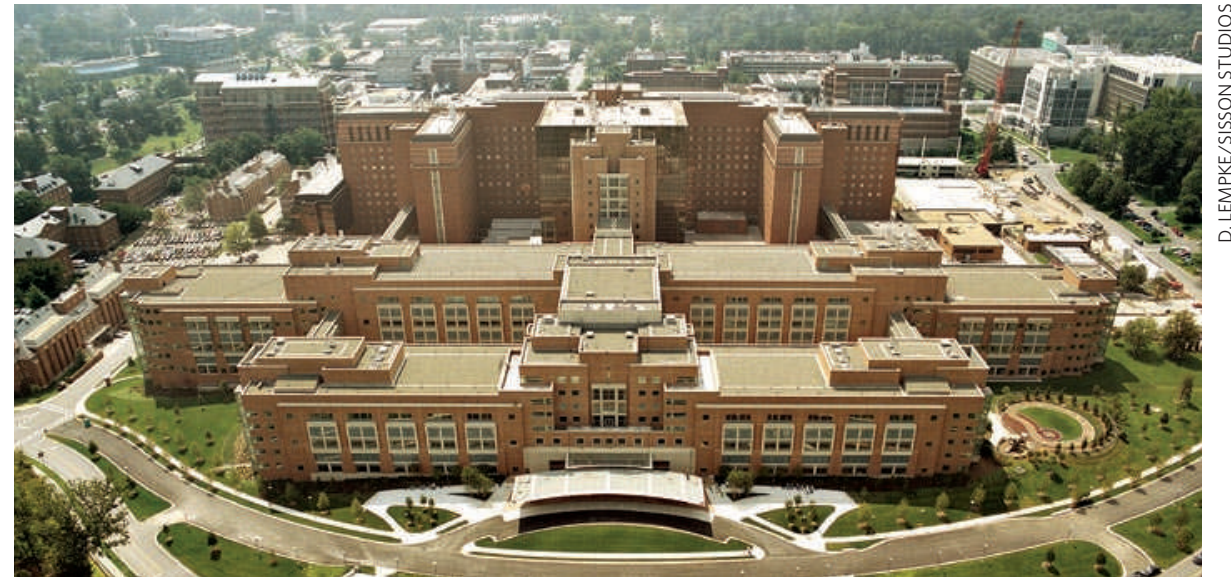

The NIH Clinical Center's Mark O. Hatfield Clinical Research Center (foreground) was opened in 2004.

"is because we can't afford to bring them in, because we have to live within our budget. At any other [US] hospital, you bring in a patient and you generate revenue. In this hospital, you bring in a patient and you generate costs."

The proposal would aim to improve use and offset some costs by allowing outside investigators to access the Clinical Center, which offers, among other things, metabolic chambers that can measure a subject's carbohydrate and fat metabolism second by second and an in-house facility that makes novel vaccines and drugs at the behest of investigators.

By sharing this trove with outside investigators, the NIH could also maximize its contribution to clinical research at a time when Congress and the US public are demanding speedier translation

\section{SOARING COSTS}

Cost increases at the National Institutes of Health Clinical Center have outpaced NIH budget growth.
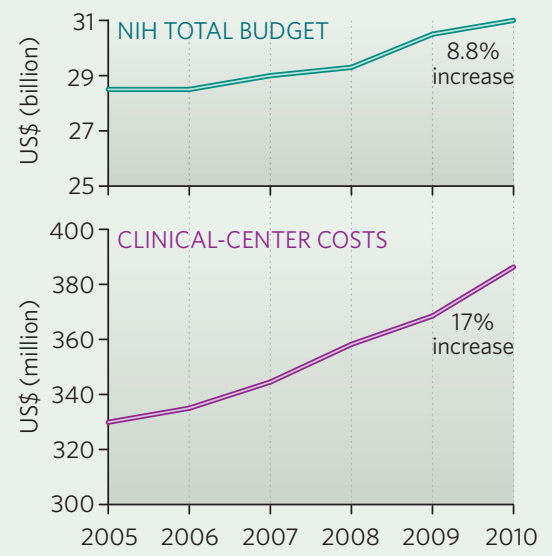

of basic research into therapies and when Collins has made this quest a top priority.

In principle, the idea is "wonderful", says Susan Shurin, acting director of the NIH's National Heart, Lung and Blood Institute, and a member of the SMRB. But the devil lies in its details, she adds. "If it doesn't benefit extramural investigators, they won't come. If it's too expensive for us, we can't have them. The financing is such a big issue that it will determine whether or not it's feasible."

Gallin is enthusiastic about opening the centre's doors to outsiders. "We are still working on the fee structure, but the concept is that it should be viewed as really cheap," he says.

That makes other institute directors worry that studies by outside investigators could draw resources from already challenged NIH institute research budgets. "The institutes have serious concerns about the obligations that they would incur in terms of providing support," said one institute director who declined to be named.

Translational-research advocates say that the benefits of opening the centre to a broader community make it worth sorting through the tangle of logistical issues. "These were taxpayer dollars that created this resource. Let's figure out how we benefit clinical research and ultimately patients," says Margaret Anderson, the executive director of FasterCures in Washington DC, one of 87 disease advocacy groups that wrote to Collins in May, urging him to open the centre's doors to outside investigators.

The SMRB is set to vote on the proposal in September. The decision on whether to act on its recommendations will rest with Collins. Meredith Wadman 